\title{
Trans Radial Access for Diagnostic Coronary Angiography and Percutaneous Coronary Interventions: Current Concepts and Future Challenges
}

\author{
Deepak Natarajan \\ Moolchand MedCity \\ New Delhi \\ India
}

\section{Introduction}

Transradial approach (TRA) for diagnostic coronary angiography was first used as early as 1948(1) but was soon abandoned for larger access vessels such as femoral and brachial arteries because catheters then used were too large and cumbersome to be routinely used for radial artery cut down. The radial access technique was re-introduced 2 decades ago and has since then been employed both for diagnostic coronary angiography and percutaneous coronary intervention (PCI). It is however still not as popular as the femoral artery approach (FA) in most parts of the world. The femoral artery has conventionally been the most popular approach despite some limitations, such as presence of peripheral artery disease, anticoagulated patients, obese patients or those who have orthopedic problems of the spine or hip. The patient, with FA, has to lie down for several hours post procedure and this can be arduous in the presence of congestive heart failure or lung disease. The duration of recumbency with the femoral approach albeit shortened by closure devices but controlled trials have yet to demonstrate significantly reduced access site complications, and also such devices are not employed all over the world.

Professor Lucien Campeau, a French Canadian physician described coronary angiography by TRA in 1989 (2-3) and Professor Ferdinand Kiemeneij in Amsterdam performed successful PCI for the first time using the radial approach in 1993(4). Keimeneij also conducted a randomized study involving 900 patients comparing trans femoral, trans brachial and trans radial approaches in patients undergoing percutaneous coronary angioplasty (PTCA). All 3 approaches had equivalent clinical outcomes but local access site complications were substantially less in the TRA subgroup (5).

The TRA has certain advantages over the conventional FA. The radial artery is close to the skin surface and can therefore be more easily palpated and punctured. The radial artery can be easily compressed post procedure and the patient is almost immediately mobile. Moreover the patient can be discharged in a couple of hours after diagnostic coronary angiography and the next day if he has undergone PCI. 


\section{Allen test}

Traditionally cardiologists confirm dual supply to the hand by radial and ulnar arteries by performing the Allen's test (6-7). The hand is supplied by both radial and ulnar arteries. The radial artery is hence not an end artery like the femoral or brachial arteries. In the event of radial artery block, albeit quite uncommon, the hand continues to get blood supply via the ulnar artery.

Many, but not all, interventional cardiologists therefore check for ulnar collateral supply before a procedure by the Allen's test. Both arteries are compressed firmly till the palm of the hand blanches. The ulnar artery is suddenly released and if the palm regains color quickly (within 8-10 seconds) the ulnar artery is patent. Another method, probably more objective is to check waveforms and oxygen saturation by a pulse oximetry/plethysmography. Rapid reappearance, on release of ulnar artery compression, of arterial pulse waveform documented by an oxygen saturation probe placed on the index finger confirms patency of the ulnar artery (Figures 1-5). Some operators in recent times however have done away with assessing dual hand circulation and almost $30 \%$ no longer bother with the Allen test (8).

\section{Radial puncture}

The first step is the preparation and draping of the wrist (usually right) and the radial artery is punctured with a needle with or without the use of local anesthesia. The needle varies in length form 2-4 cms and 19-21 gauge. Some operators prefer the shorter needles because it is easier to pick the flash of blood observed on puncturing the radial artery. Operators in Asia prefer a hydrophilic sheath covered needle. Patient discomfort is minimal and radial artery spasm non-existent. An introducer wire is threaded through the needle into the radial artery and minute quantity of local anesthesia $(1-2 \mathrm{ml})$ is administered (if not given earlier) at the base of the needle with the introducer wire. Next a tiny superficial incision is made on the skin ensuring the radial artery is not damaged. The puncture by the needle is usually made 2-3 cms above the radial styloid. A dedicated $5 \mathrm{Fr}$ or $6 \mathrm{Fr}$ sheath is introduced into the radial artery, 1,000 -2,000 units of heparin and 50-100 mcg of nitroglycerine administered intra arterially to prevent thrombus and spasm .The arterial sheath, $5 \mathrm{Fr}$ or $6 \mathrm{Fr}$, is connected to the pressure transducer to confirm radial artery entry pulse waveform (Figures 6-9).

\section{Coronary angiography}

We use the Tiger II (Terumo) catheter to hook both left and right coronary arteries during diagnostic coronary angiography, while PCI is performed by standard 6 Fr left and right guiding catheters (Judkins, XB, Amplatz left, EBU and Kimny). Once radial access has been successfully achieved it is easy to navigate diagnostic and guide catheters through the brachial, axillary and subclavian arteries into the ascending arch of aorta. It is important to visualize the negotiation of the catheter right from the wrist to the aorta under fluoroscopy Direct visualization ensures the correct route is adopted preventing vascular complications (Figures 10-15). The right radial artery is preferred by most operators while the left artery is avoided in patients with compromised kidney function as it may be needed for a future arterio-venous shunt. Similarly the left renal artery is not employed in a prospective coronary bypass surgery patient who may need a radial graft. The left radial approach however is particularly helpful for left internal mammary artery PCI, and with traditional diagnostic and guide catheters( Judkins,EBU,XBU etc) are used. 


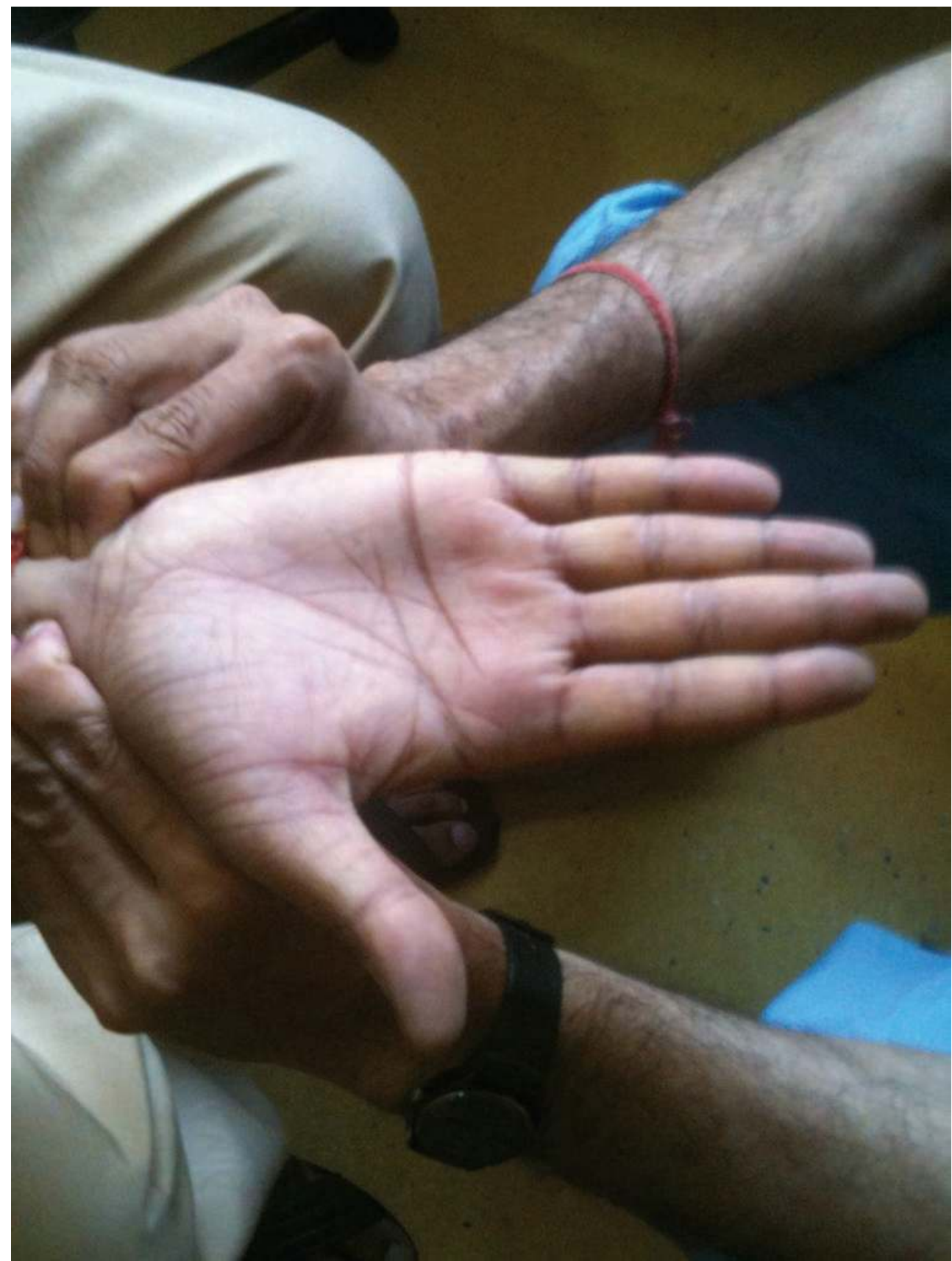

Fig. 1. Blanching of palm with simultaneous compression of radial and ulnar arteries in the right wrist 


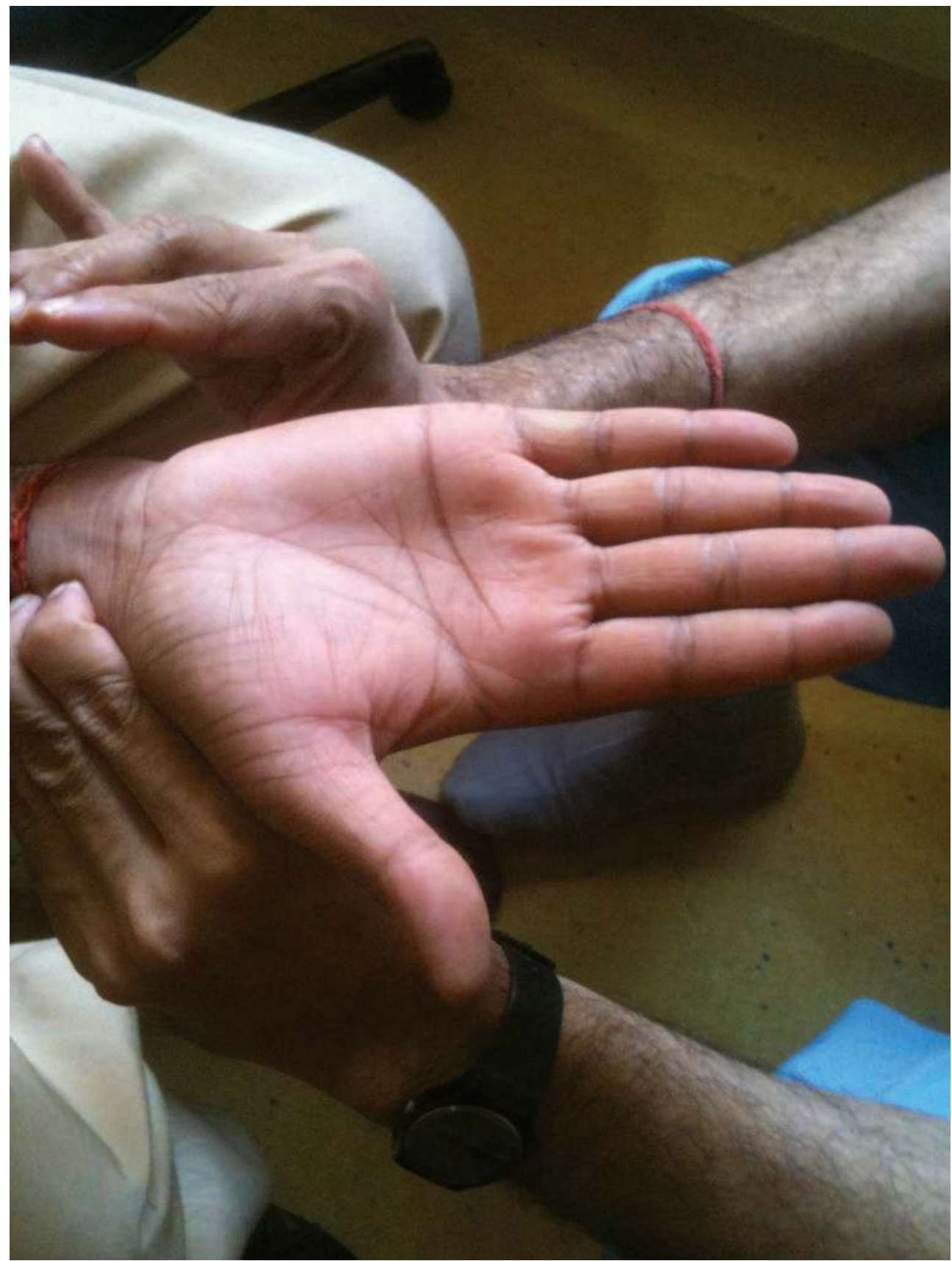

Fig. 2. Recovery of color of the palm on release of ulnar artery suggesting normal ulnar collateral flow 


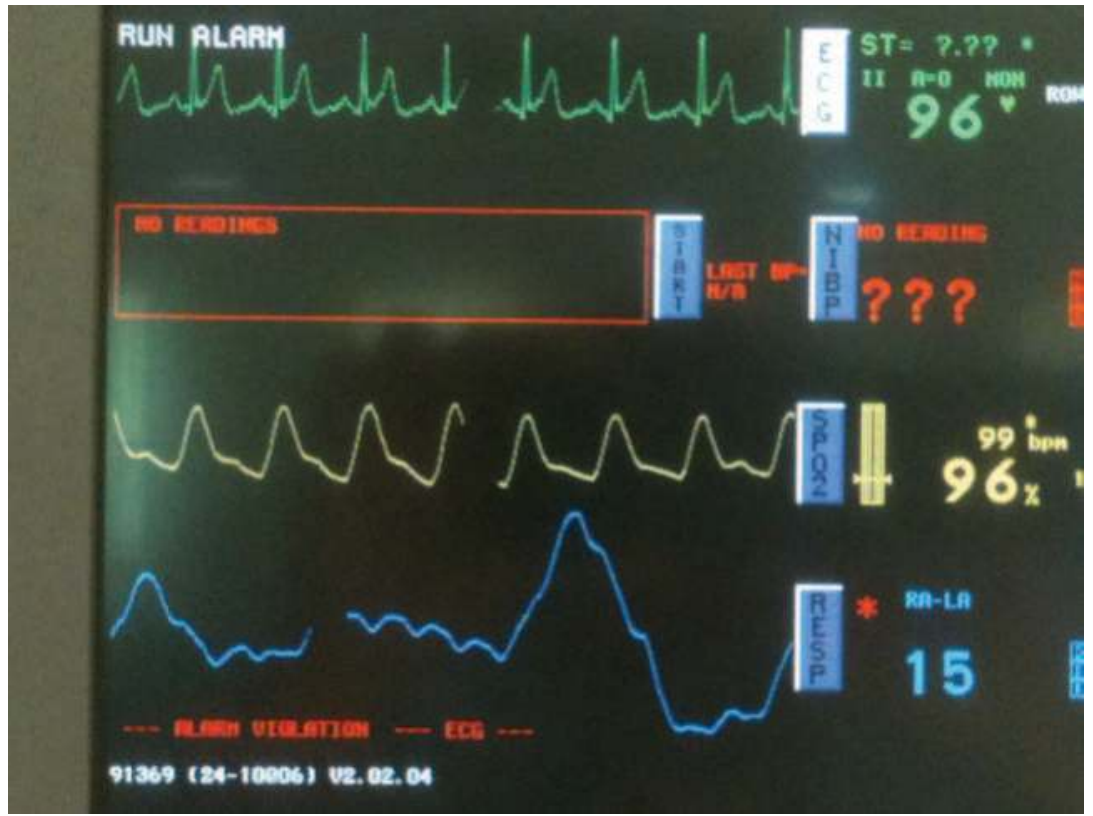

Fig. 3. Normal pulse waveform and oxygen saturation before Allen test

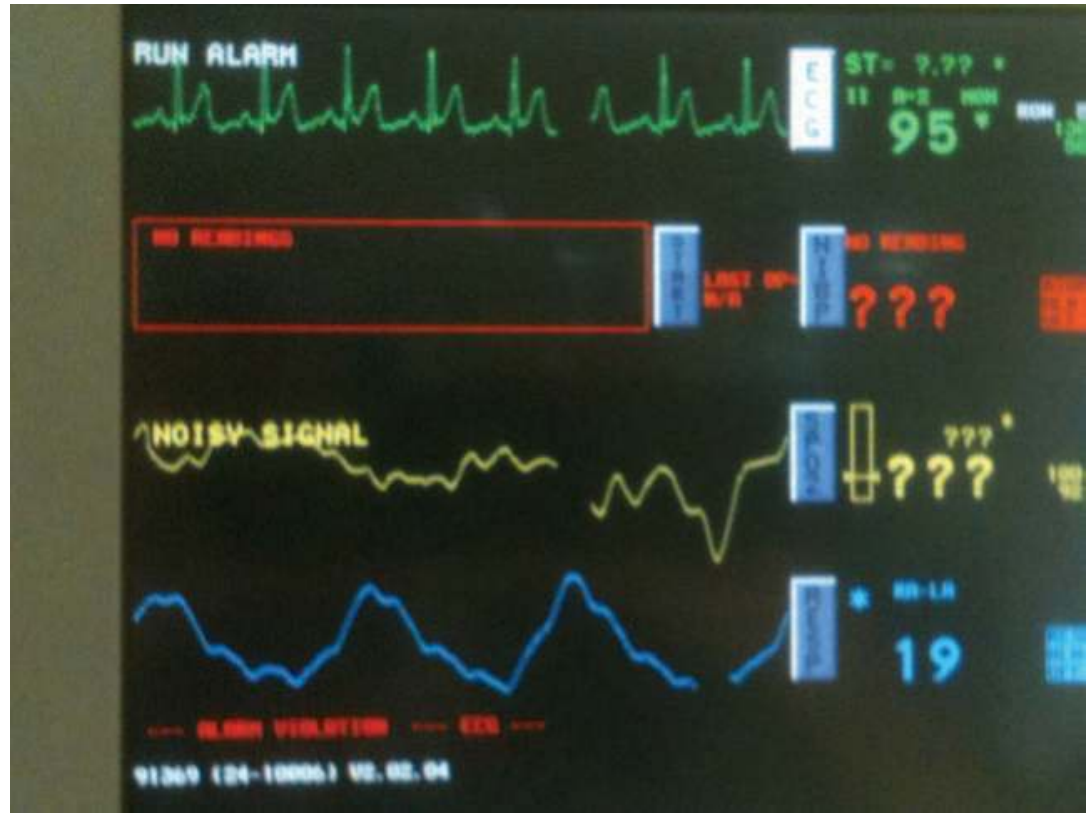

Fig. 4. Disappearance of pulse waveform and inability to read oxygen saturation on compressing radial and ulnar arteries 


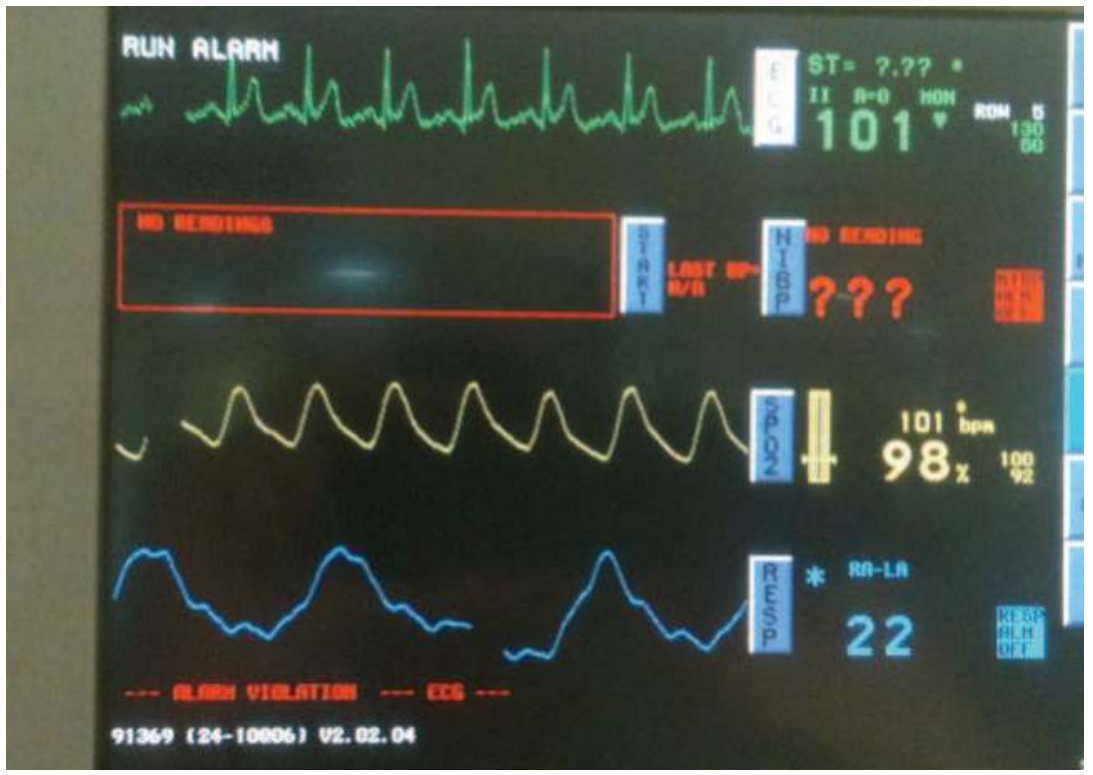

Fig. 5. Prompt recovery of pulse waveform and oxygen saturation on release of ulnar artery

\section{Hemostasis}

Ensuring complete hemostasis requires simple manual compression because the radial artery is both small and superficial. The earlier practice of administering nitroglycerin and verapamil just prior to sheath removal has also been largely abandoned. In the rare case where vessel spasm is encountered during the procedure nitroglycerin can be useful. Radial artery block subsequent to coronary angiography or PCI is also extremely uncommon. Temporary radial artery block occurs in $5 \%$ of patients and can be reduced with pre procedural usage of heparin. In fact more than $50 \%$ of TRA operators do not ascertain the incidence of radial artery obstruction subsequent to a procedure or prior to hospital discharge.

Almost $90 \%$ of operators use the right radial artery initially and $31 \%$ cross over to the contra lateral radial artery if unsuccessful. Fifty four percent of operators opt for the femoral artery in case of initial radial access failure.

\section{Discharge}

Same day discharge is quite common especially post diagnostic coronary angiography and a substantial number of patients undergoing PCI can also be discharged the same or the following day. Randomized studies have established the safety of same day discharge in patients of acute coronary syndrome (ACS) after uncomplicated PCI (22).

\section{Reduction in bleeding complications with RTA as compared to femoral route}

Recently it has been recognized that major bleeding results in an odds ratio of 3.5 for inhospital and 1 year mortality. Surprisingly the hazard at 1 year was greater than that 


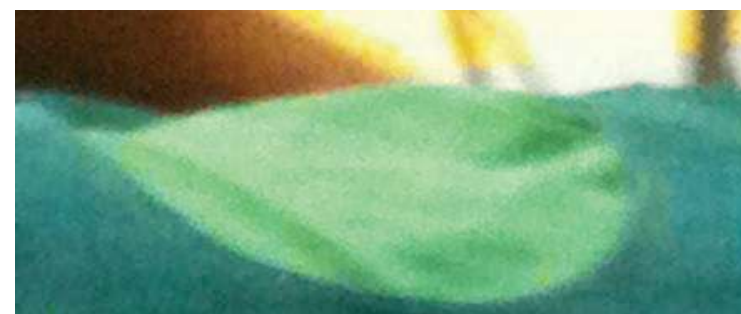

Fig. 6. The right wrist sterilized and draped before radial puncture 


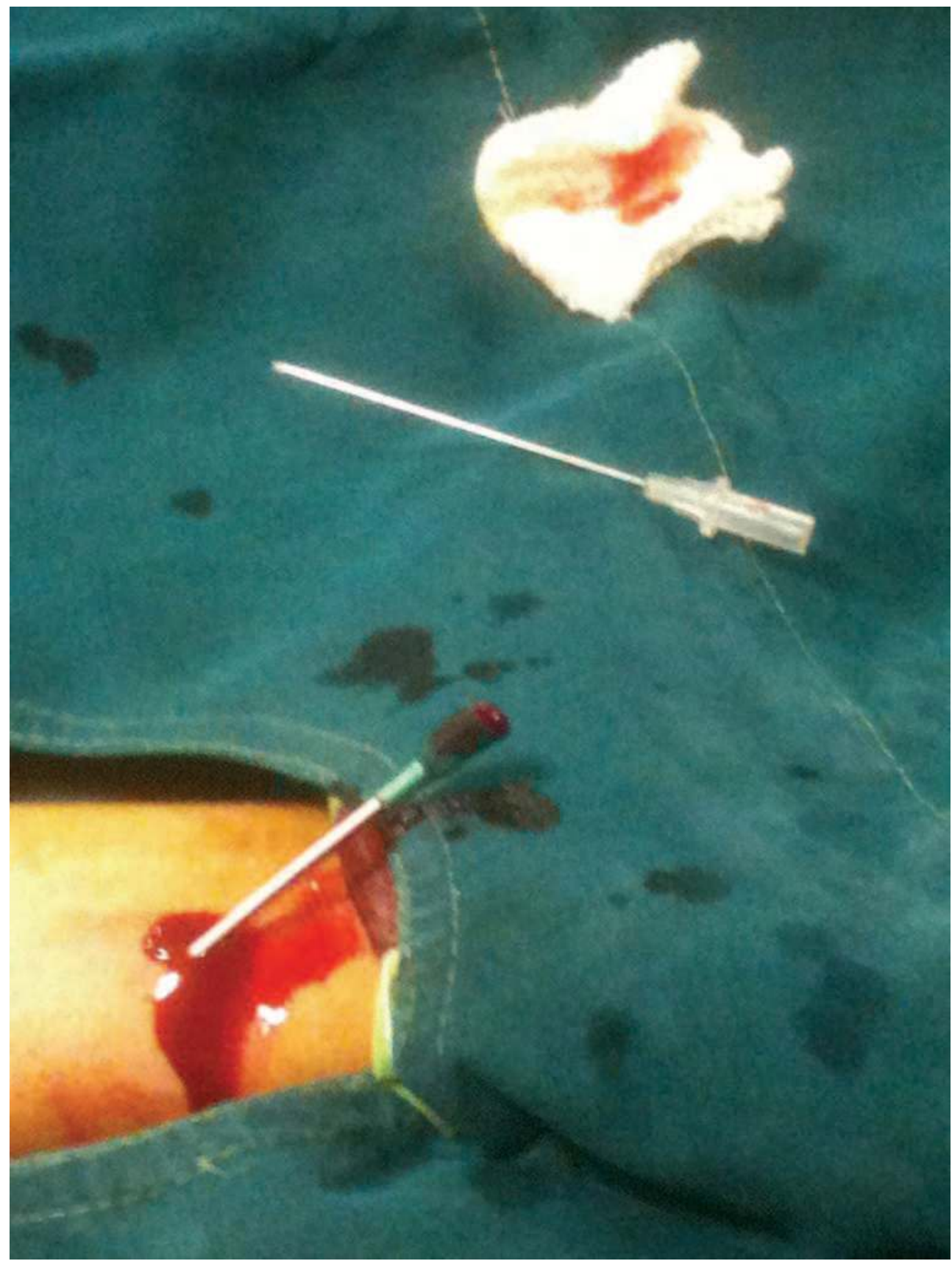

Fig. 7. Radial artery successfully punctured by needle/sheath and the needle removed with sheath in artery lumen displaying back flow of arterial blood 


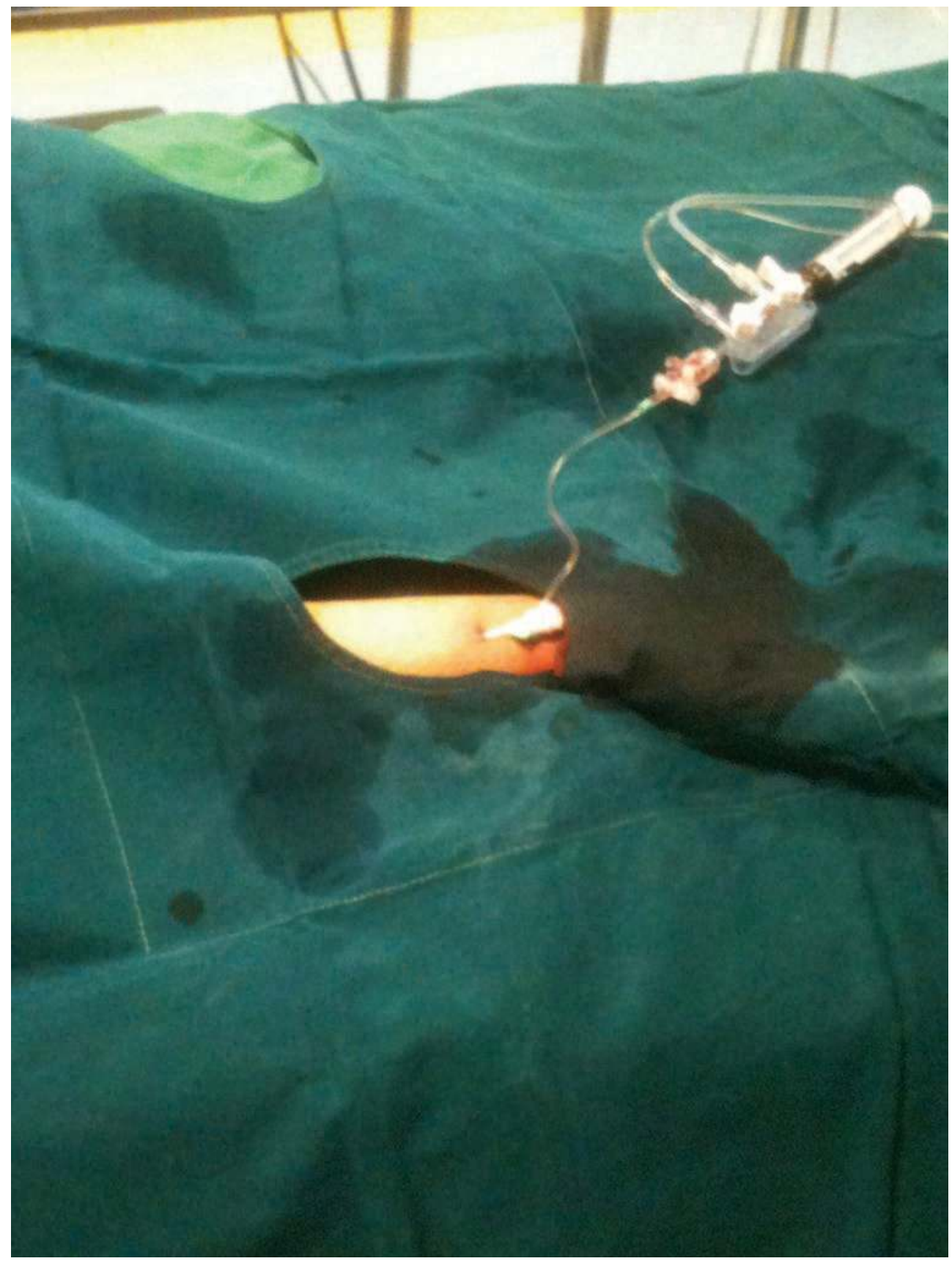

Fig. 8. The 6 Fr arterial sheath is connected to pressure transducer 


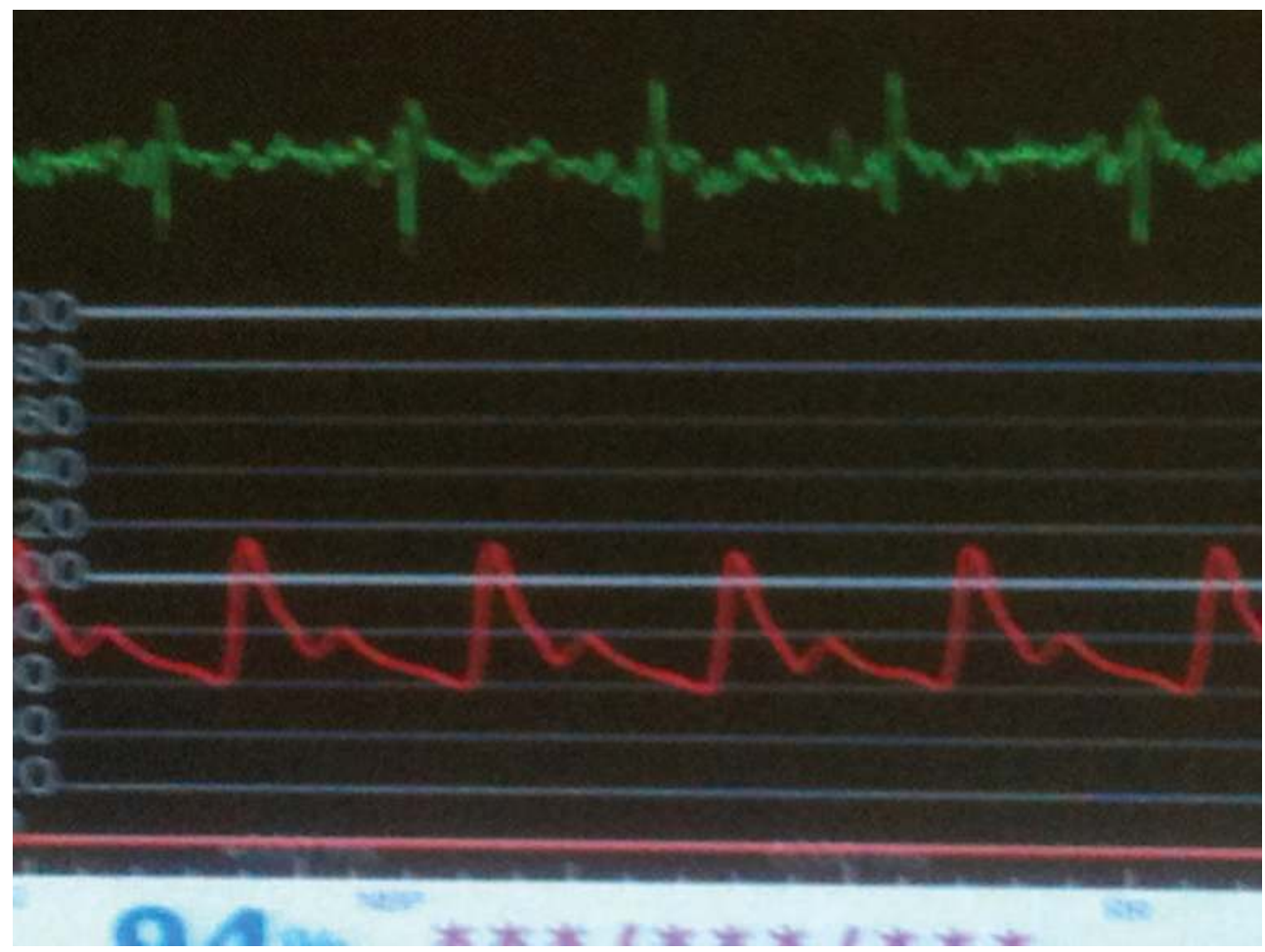

Fig. 9. Good radial artery waveform seen suggesting sheath is in intra luminal

observed with ischemic complications and reinfarction. Bleeding complications and transfusions have been identified as independent predictors of adverse outcomes in the recent OASIS-5 (Organization for the Assessment of Strategies for Ischemic Syndromes) and ACUITY (Acute Catheterization and Urgent Intervention Triage Strategy) trials (9-12). The HORIZONS AMI, a large randomized study comparing bivalirudin with a combination of heparin and Glycoprotein 2b/3a inhibitors also documented that significantly less major bleeds with the former led to reduced mortality at 30 days and at the end of one year (13).

The underlying mechanism for increased mortality accompanying major bleeds is unclear. The working hypothesis is that gastrointestinal or retroperitoneal bleeding during FA causes rapid loss of blood volume and oxygen carrying capacity that at times necessitates blood transfusion. Hypotension leads to reduced perfusion and the tendency to stop oral antiplatelets renders the bleeding patient more vulnerable to stent thrombosis. Moreover transfusion itself is associated with increased mortality probably due to the fact that stored red blood cells lose their flexibility and thereby their ability to negotiate the small sized capillaries in the microcirculation. Red cells also have depleted nitric oxide stores and are therefore unable to facilitate vaso dilatation in the capillaries. The net effect is aggravation of ischemic complications.

Bleeding in patients with ACS is a powerful determinant of fatal and non-fatal outcomes Approximately $5 \%$ of ACS patients develop major bleeds and suffer increased mortality by 5 times in the next 30 days. 
Femoral punctures may result in local hematoma, pseudo aneurysm, arterovenous fistula, and worse retroperitoneal hemorrhage. The single most effective method of avoiding these complications is to employ TRA for diagnostic angiography and PCI. A systemic review of randomized trials has shown reduction of access site complications by $80 \%$ when the radial route instead of the femoral artery was employed $(p=0.0001)(20)$.

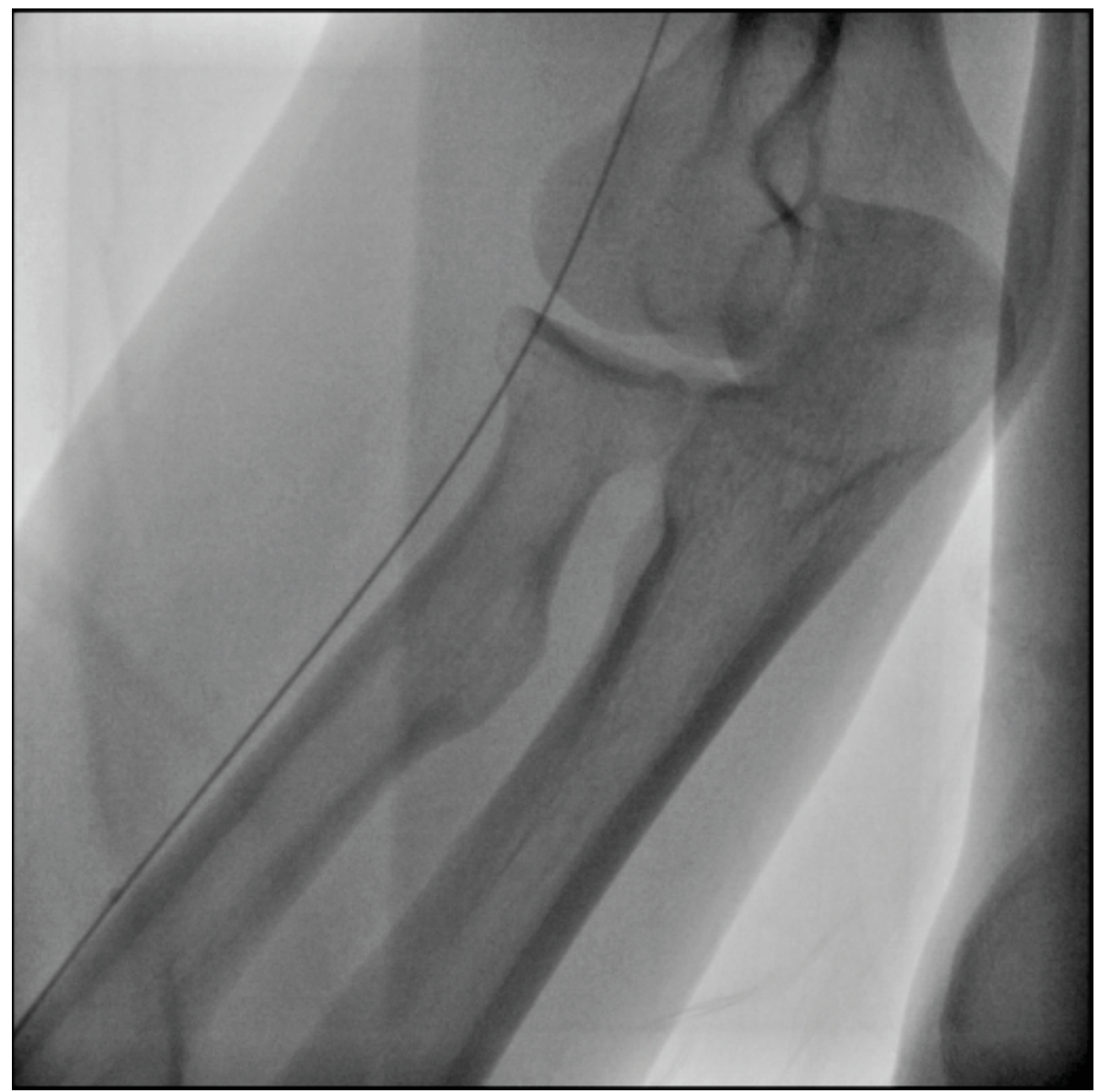

Fig. 10. Guide wire is being navigated through right brachial artery under fluoroscopy

The MORTAL (Mortality Benefit of Reduced Transfusion after PCI via the Arm or Leg) study retrospectively studied both approaches in 32,000 patients who underwent PCI in British Columbia from 1991 to 2005. Radial access approach resulted in 50\% reduction in blood transfusion rate and a relative reduction in 30-day and 1-year mortality rates of $29 \%$ and $17 \%$ respectively $(\mathrm{p}<0.001)(15)$. 


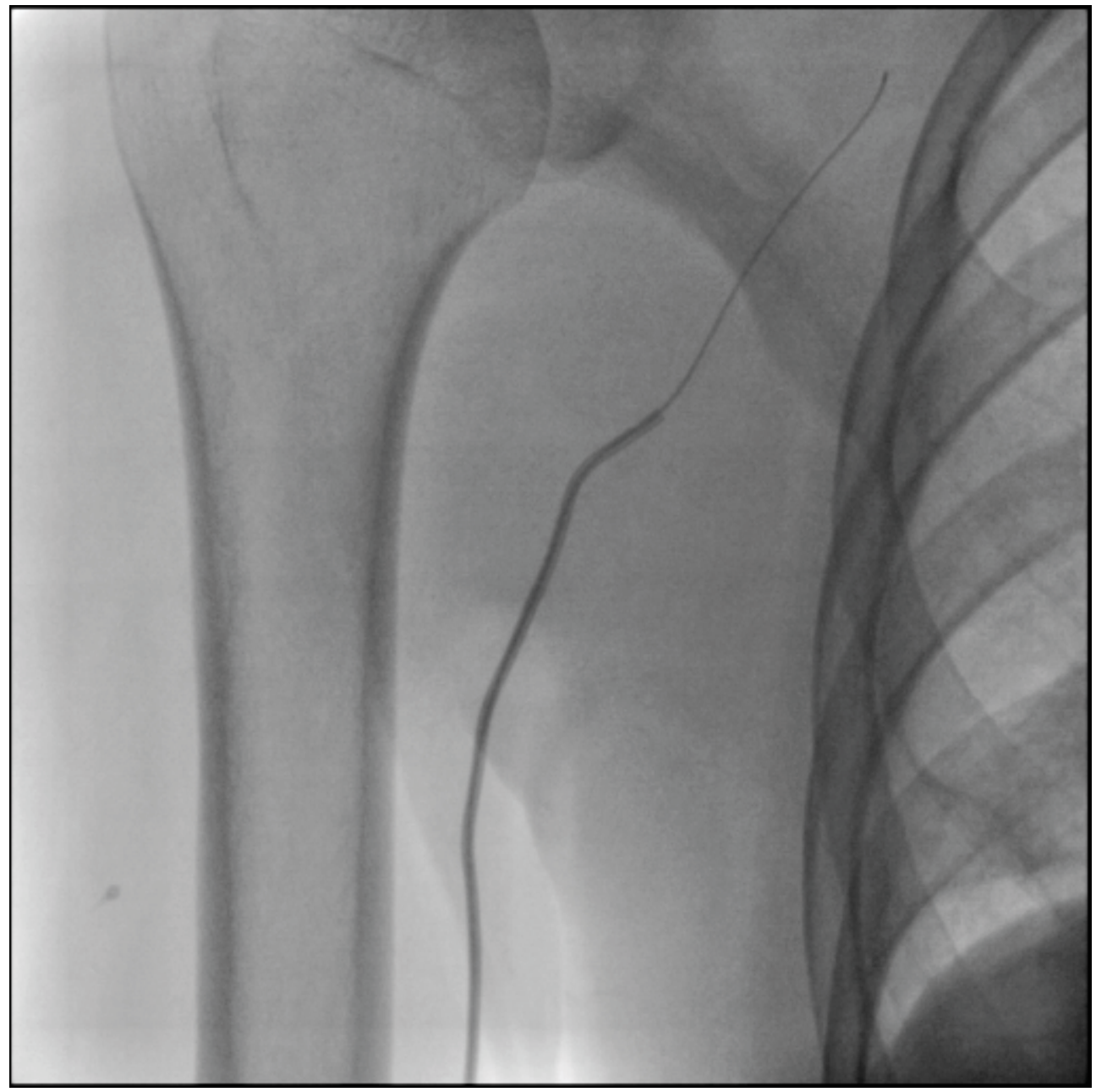

Fig. 11. Guide wire with Tiger II diagnostic catheter is now in right axillary artery

The MORTAL data was endorsed by the RIVIERA (Registry on Intravenous Anticoagulation in the Elective and Primary Real World of Angioplasty), a prospective international registry that reported reduction in bleeds and transfusions with the radial approach resulted in reduced PCI related mortality (16).

The Radial Access versus conventional Femoral Puncture: Outcome and Recourse Effectiveness in a Daily routine Practice (RAPTOR) trial explored whether it is feasible for an interventional center with operators experienced with FA to convert to RA routinely in a real world strategy. This was a prospective randomized trial comparing radial access with FA in an unselected population. Exclusion criteria included an abnormal Allen's test, end stage renal disease, planned coronary bypass surgery, pregnancy and hyperthyroidism. The mean age was 65 years and failure to gain access occurred in $3.4 \%$ of femoral patients and in $3.6 \%$ of the radial patients (non significant difference). 


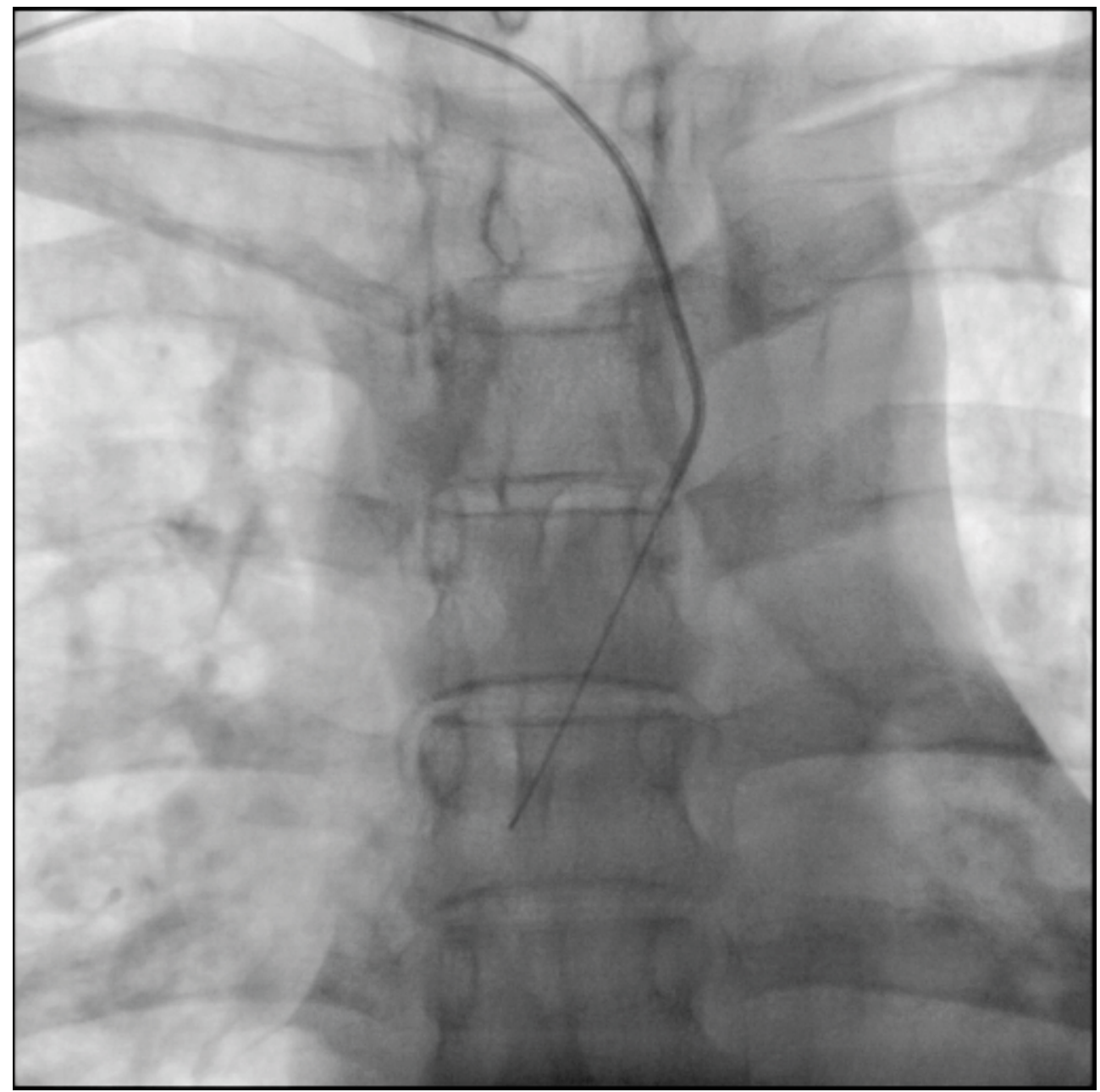

Fig. 12. Diagnostic catheter being negotiated into ascending aorta

It took 3 more minutes to get RA than the FA and 2 more minutes to perform diagnostic coronary angiogram. However time taken for PCI was almost similar by both routes (37 min by FA versus 34 min by RA; $p=0.2$ ). Radiation times and doses were significantly more in patients undergoing RTA during diagnostic coronary angiography (6.4 minutes versus 4.4 minutes, and 30 Gy cm sq versus $23 \mathrm{~Gy} \mathrm{~cm} \mathrm{sq;} \mathrm{p}<0.01)$ ) but similar with PCI in both approaches. The RAPTOR study underscored the fact that experienced interventional cardiologists could convert to the RA approach quite comfortably and easily on a routine basis (17).

Every study describing RA technique for coronary angiography and coronary intervention has highlighted the substantial reduction in local vascular complications and bleeding. There is also the added advantage of patient comfort but neither the TRA nor the FA can be used in $100 \%$ of patients. There will always be difficulties with one of them necessitating converting to the other approach. 


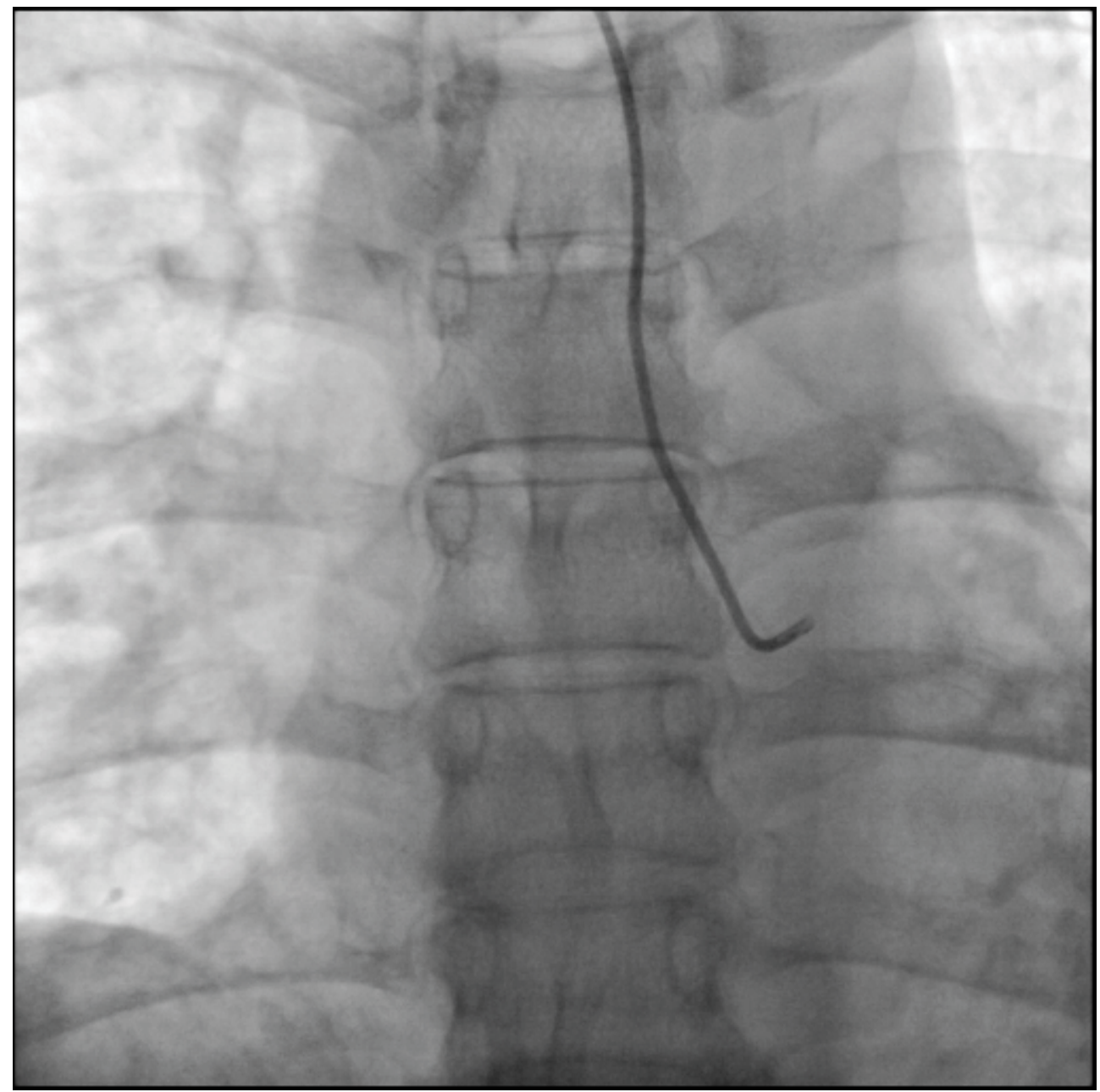

Fig. 13. Tiger II diagnostic catheter about to engage left coronary artery

Brueck et al in a randomized study comparing the 2 approaches showed that the femoral approach had 6 times the vascular access site complications $(3.7 \%$ vs.6\%, p=0.0008) compared to the radial group. Femoral access had slightly higher procedural success rates $(99.8 \%$ transfemoral vs. $97 \%$ TRA, $\mathrm{p}<0.001)$ and lesser radiation exposure $(42 \mathrm{Gycm} . \mathrm{sq}$ vs. 38 Gycm.sq)(21).

Jolly et al in a meta-analysis of randomized trials reported that PCI with radial artery access reduced major bleeding $73 \%$ compared to $\mathrm{FA}(0.05 \%$ vs. $2.3 \%, \mathrm{p}<0.01)$ and also demonstrated a trend in reduction in the composite of death, myocardial infarction and stroke $(2.5 \%$ vs. $3.8 \%, \mathrm{p}=0.058)$. There was no difference in mortality between the 2 techniques but TRA reduced hospital stay by 0.4 days (20).

The largest multi-centric randomized study to date is the radial versus femoral access for coronary angiography and intervention in patients with acute coronary syndromes (RIVAL). 


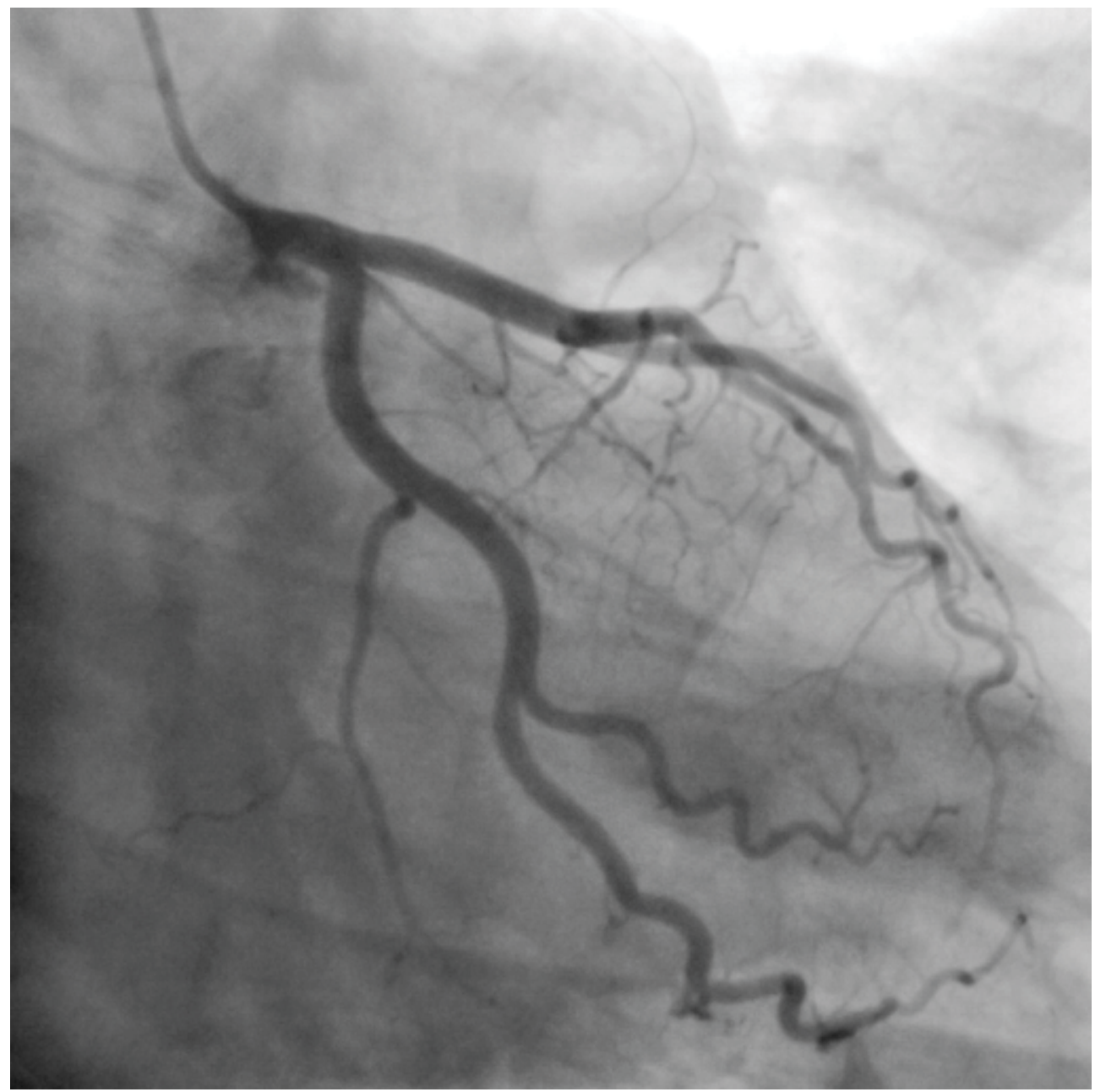

Fig. 14. Normal left coronary artery seen in right anterior oblique/caudal view

Patients were randomly assigned (1:1) to radial or femoral access. The primary outcome was a composite of death, myocardial infarction, stroke, or non -CABG related bleeding at 30 days. Patients were enrolled from 158 hospitals in 32 countries. The primary outcome occurred in 128 ( $3.7 \%$ ) of 3507 patients in the radial access group compared to 139 ( $4 \%$ ) of 3514 in the femoral access group ( hazard ratio HR 0.92, 95\% CI 0.72-1.17; $\mathrm{p}=0.5)$.Interestingly of the 6 pre-specified subgroups, there was significant interaction for the primary outcome with benefit for radial access in highest tertile volume radial centers ( HR 0.49, 95\% CI 0.28=0.87; $\mathrm{p}=0.015$ ) and in ST-segment elevation myocardial infarction (HR 0.60 , CI 0.38-0.94; $\mathrm{p}=0.026$ ). The rate of death, myocardial infarction, or stroke at 30 days was $112(3.2 \%)$ in the RA group compared to $114(3.2 \%)$ in the FA group. The rate of non CABG related major bleeds at 30 days was $24(0.7 \%)$ in the RA group as compared to $33(0.9 \%)$ in the FA group $(p=0.23)$. Large hematoma were significantly less in the RTA group (HR $0.73,95 \%$ 


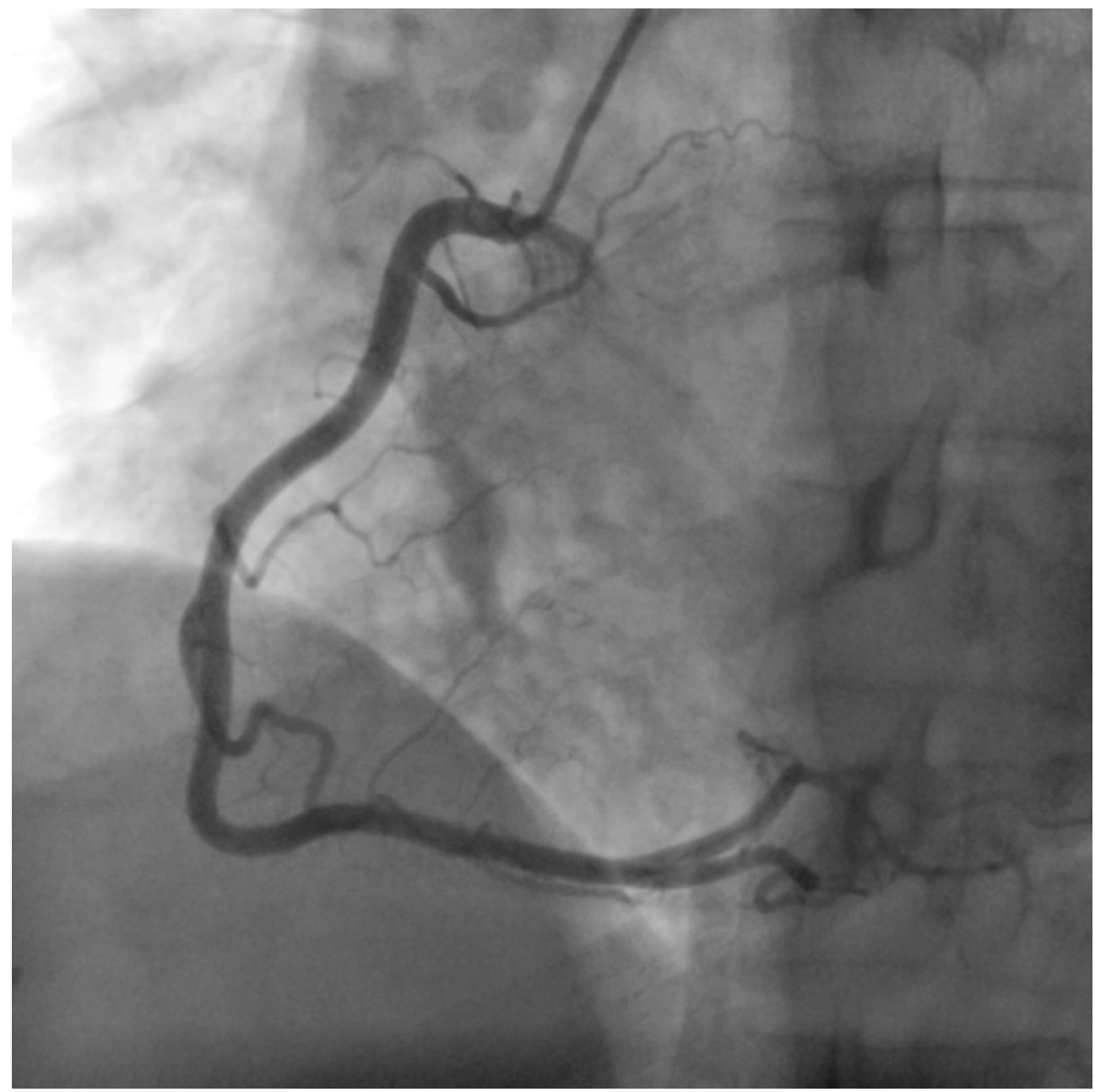

Fig. 15. Normal right coronary artery flow seen in left anterior oblique view

CI $0.28-0.57$; $\mathrm{p}<0.0001$ ) as also pseudoaneurysm requiring closure were significantly less again in the RTA group (HR 0.30, 95\% CI 0.13-0.71; p=0.006).

The RIVAL study concluded that both radial and femoral approaches are safe and effective for PCI but the radial approach may be preferred because of significantly less local vascular complications (22).

Recently Swedish authors reviewed all ST-segment elevation myocardial infarction procedures conducted in Sweden (SCAAR registry) between 2005 and 2010. The radial approach for STEMI patients increased from $12 \%$ to $50 \%$. Both 30-day and 1-year mortality were significantly lower in the radial group in a study cohort of 21,339 patients (29). Both serious bleeding and hospital stay were also lessened significantly by the radial approach. The radial access approach had the best results in patients of STEMI above 70 years and in women. 


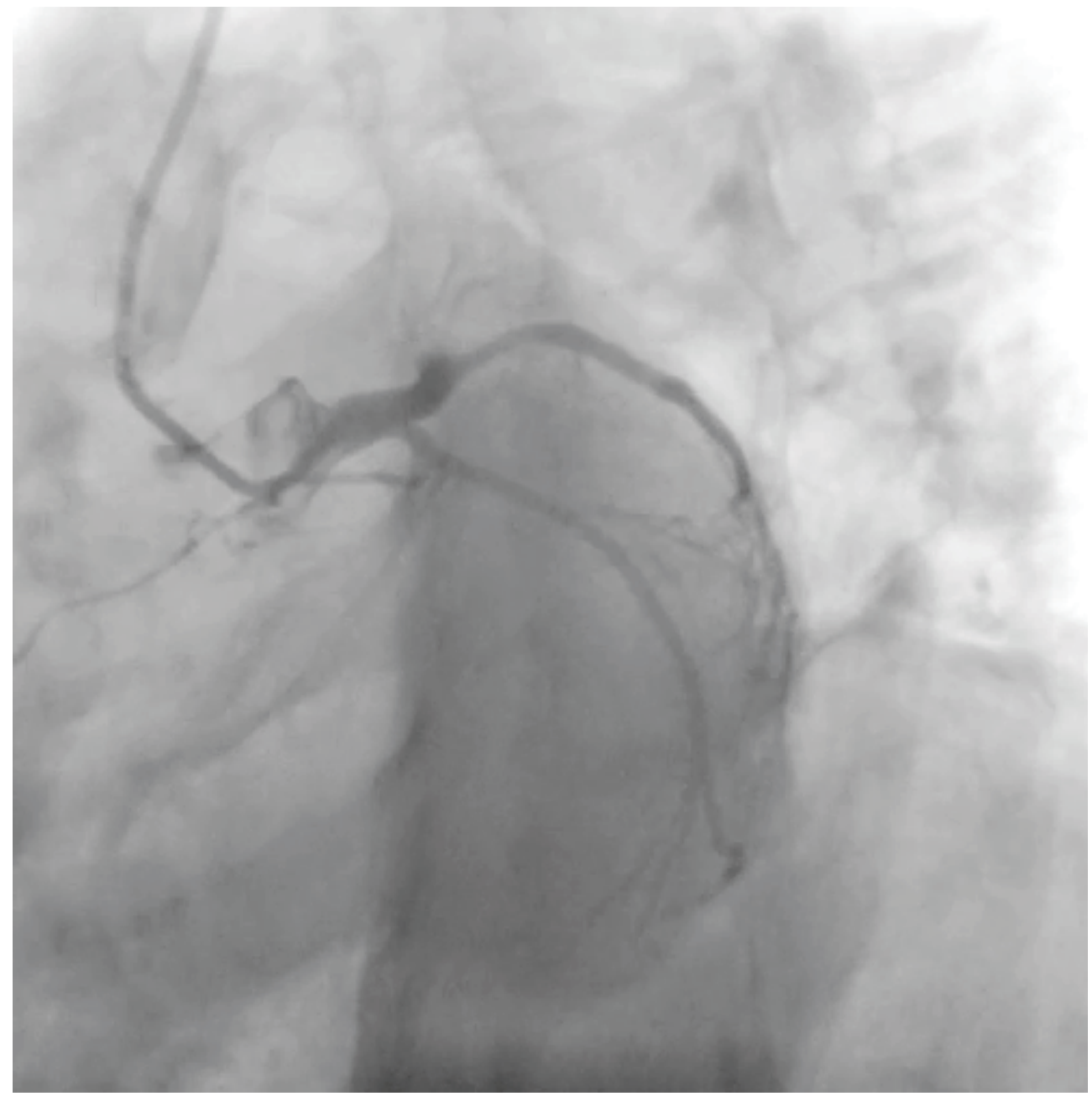

Fig. 16. Totally occluded proximal left anterior descending artery in a patient of acute anterior STEMI seen in left anterior oblique/ caudal view (Tiger diagnostic catheter)

Most complex PCI's can be easily performed by TRA because the 6 Fr guide catheters permit rotablators, intravascular ultrasound, pressure wire, "kissing balloon" left main and also coronary graft stenting. Primary PCI for STEMI can be easily managed by radial access with superior results as compared to the femoral route (24-27) and reiterated by the RIVAL study and SCAAR registry. Superior results with RTA in patients with acute ST elevation myocardial infarction (STEMI) are understandable because these patients receiving maximum quantum of antiplatelets plus antithrombotics in order to attain the best anti ischemic outcomes are paradoxically most vulnerable to local vascular and internal bleeds (Figures 16 -21) 


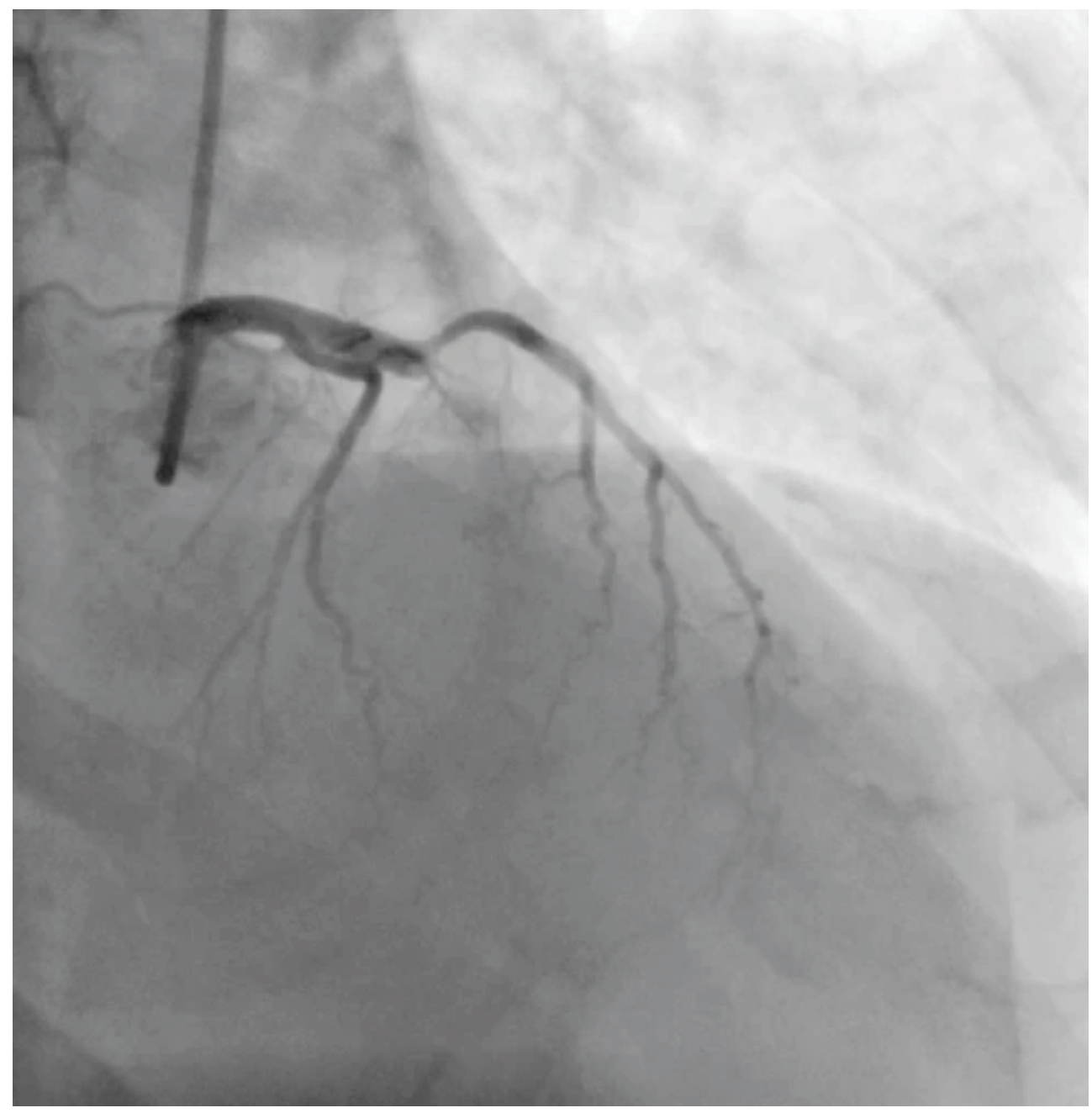

Fig. 17. Totally occluded proximal left anterior descending artery confirmed in right anterior oblique view. 


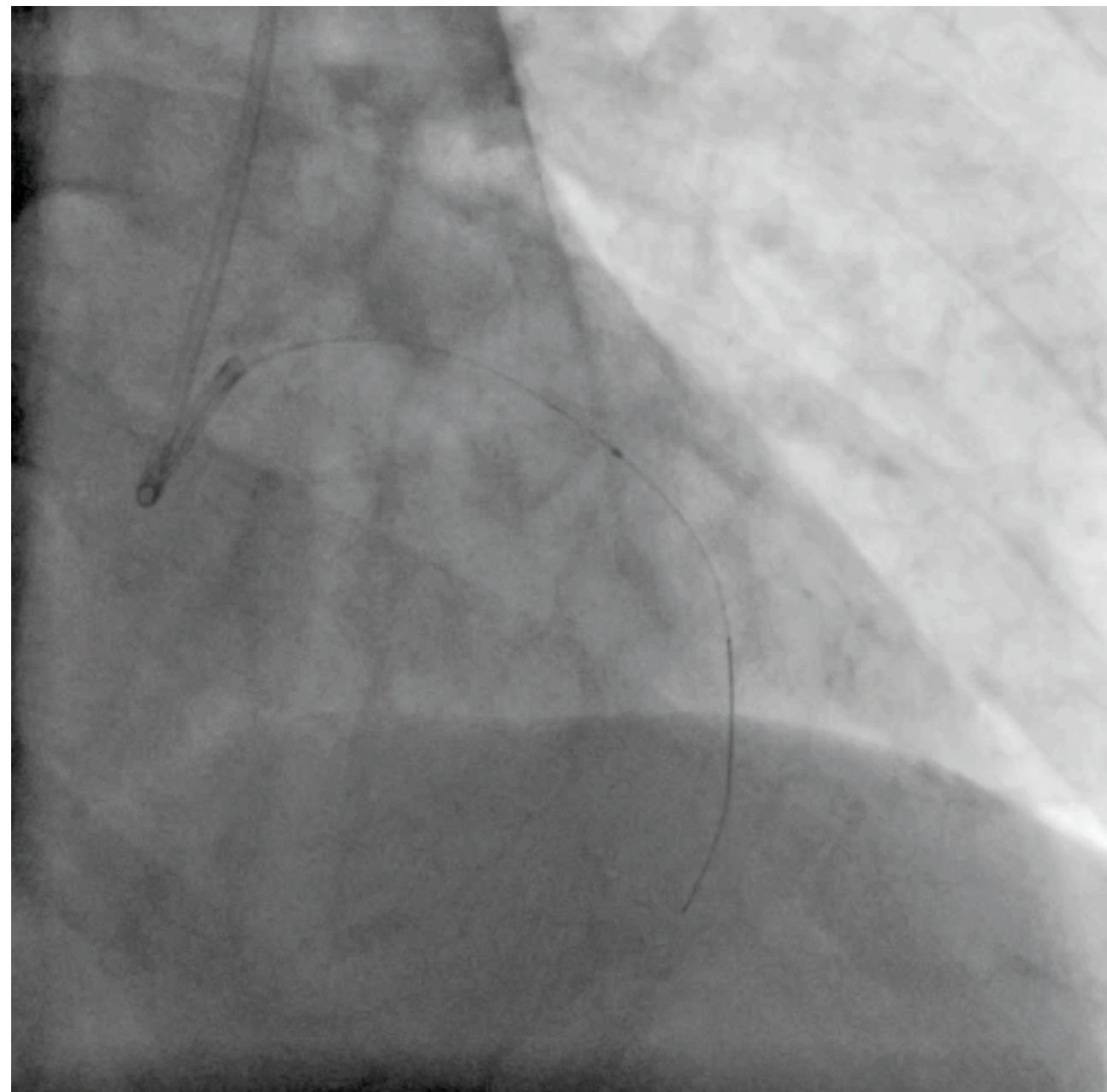

Fig. 18. A 0.012-inch guide wire is put across lesion and manual thrombo-suction being done by Export catheter via a 6 Fr EBU guide catheter 


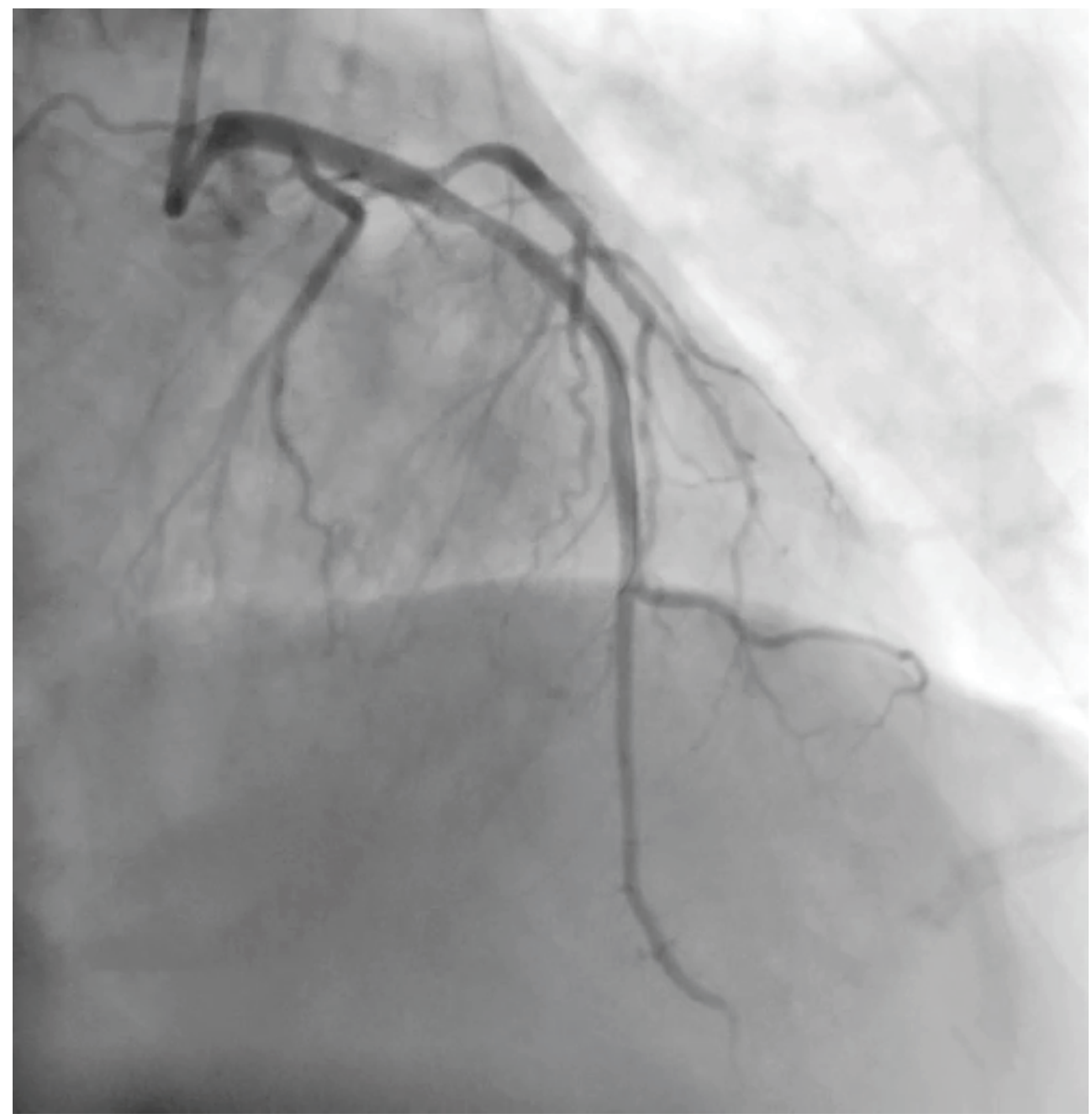

Fig. 19. Good ante grade flow post manual thrombo-suction and intracoronary Tirofiban bolus of $25 \mathrm{mcg} / \mathrm{Kg}$. 


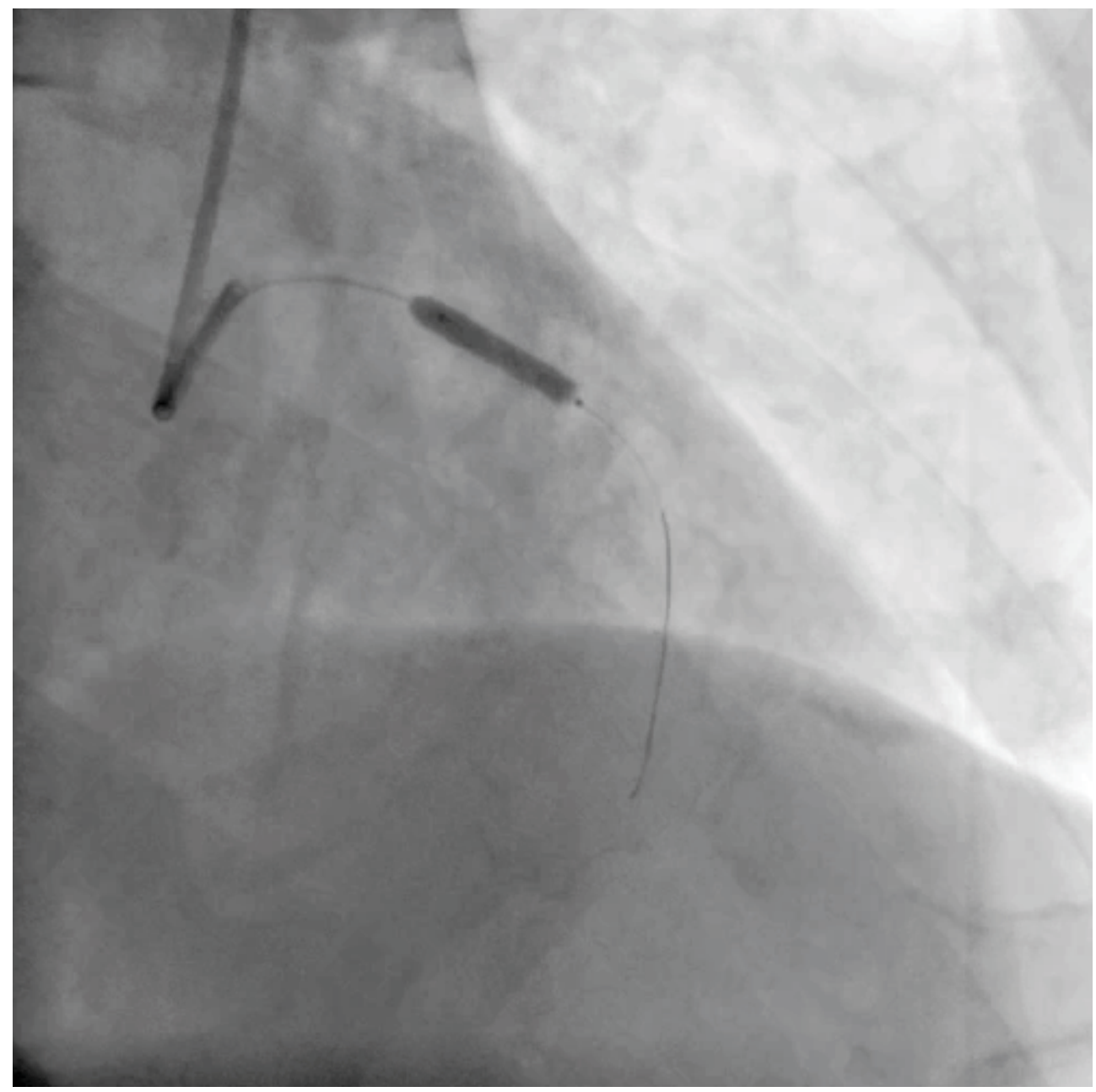

Fig. 20. Coronary stent being deployed at lesion site 


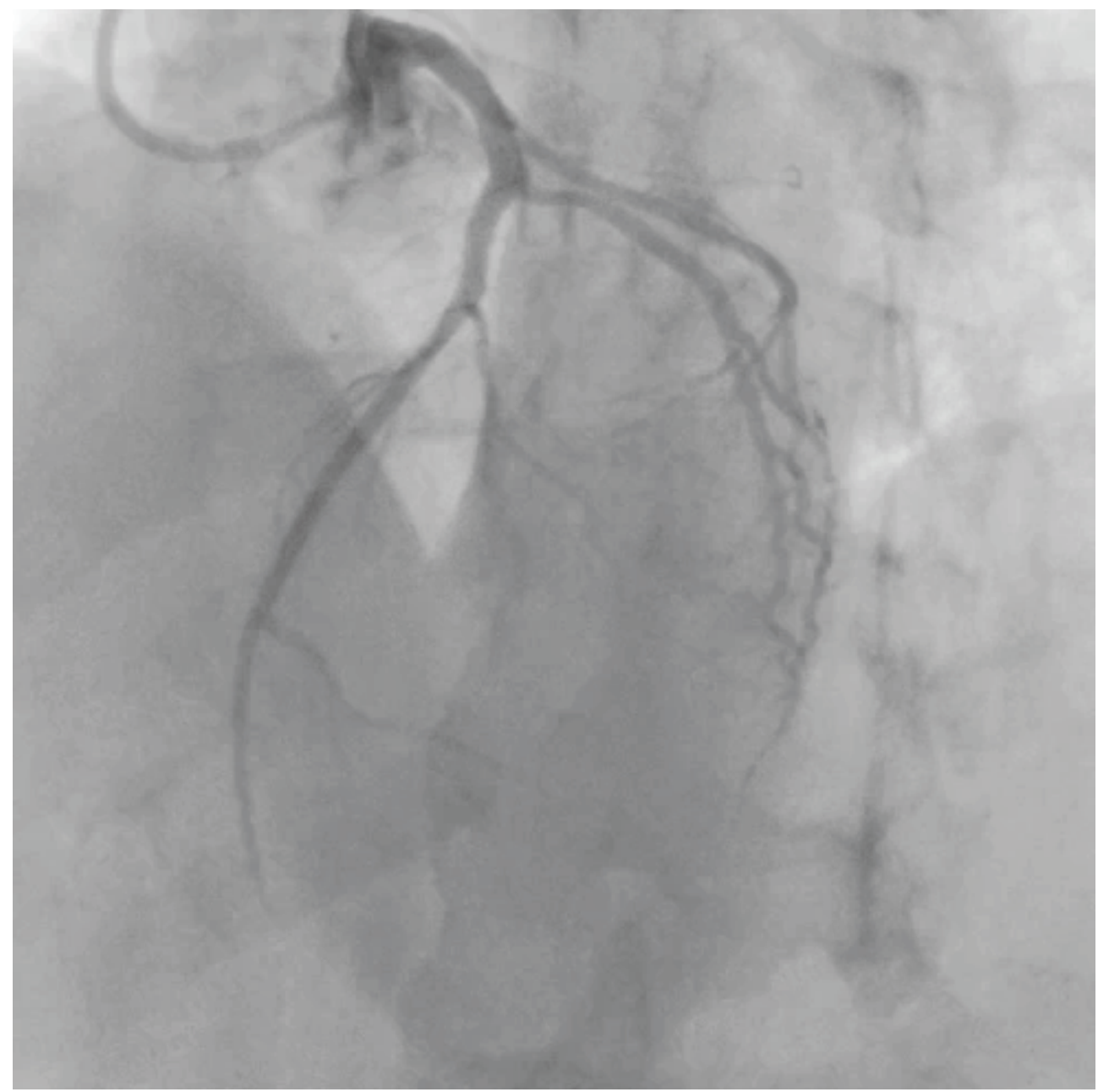

Fig. 21. Check angiogram showing brisk TIMI 3 flow with no residual stenosis

The incidence of complications when using radial access is negligible even in patients treated aggressively with anti-thrombotic and anti-platelet regimens. Patients have the added advantage of mobilization almost immediately post procedure and quicker discharge from hospital. The learning curve for the radial approach is exaggerated and most operators rapidly get comfortable and skillful with this technique (28).

The results of the first large international survey on global TRA practices were summarized as follows: 1) TRA is used by interventional cardiologists all over the world. 2) $23.4 \%$ of interventional cardiologists do not assess dual hand circulation before PCI using TRA. 3) In case of first attempt failure of TRA almost $50 \%$ resort to FA. 4) The catheters used for diagnostic coronary angiography and PCI are largely similar to the catheters used in the FA. 5) Heparin is used by more than $95 \%$ to thwart radial artery blocks. 6) Heparin remains the most employed anti thrombotic for diagnostic coronary angiography and PCI (30). 


\section{Conclusions}

It is imperative that modern interventional cardiologists be trained in both radial and femoral artery puncture techniques. The radial artery can be used for most coronary procedures as also in patients treated with maximum antithrombotic regimens (such as patients of acute coronary syndrome) because of substantial mitigation in local vascular complications. Reduction in bleeding may account for the recent superior results in patients with STEMI. Rapid mobilization with earlier discharge adds considerably to patient comfort. The radial approach is preferred in the presence of aorto iliac disease, marked obesity and high bleeding risk.

For best results one needs to be skilled in both approaches and fortunately such a trend continues to evolve in most countries.

\section{References}

[1] Radner S. Thoracal aortography by catheterization from the radial artery; preliminary report of a new technique. Acta Radiol 1948; 29:178-80.

[2] Campeau L. Percutaneous radial artery approach for coronary angiography. Cathet Cardiovasc Diagn 1989;16:3-7.

[3] Campeau L. Entry sites for coronary angiography and therapeutic interventions: from the proximal to the distal radial artery. Can J Cardiol 2001;17:319-25.

[4] Kiemeneij F, Laarman GJ.Percutaneous transradial artery approach for coronary stent implantation. Cathet Cardiovasc Diagn 1993; 30:173-8.

[5] Kiemeneij F, Laarman GJ, Odekerken T,et al. A randomized comparison of percutaneous transluminal coronary angioplasty by the radial,brachial and femoral approachesthe access study. J Am Coll Cardiol 1997;29:1269- 1275.

[6] Allen EV. Thrombangiitis obliterans: Methods of diagnosis of chronic occlusive arterial lesions distal to the wrist with illustrative cases. J Med Science 1929;178-237.

[7] Benit E, et al. Frequency of a positive modified Allen's test in 1000 consecutive patients undergoing cardiac catheterization. Cath Cardiovasc Diagn. 1996;38:352-354.

[8] Ghuran AV,Dixon G, Holmberg S,etal. Transradial coronary intervention without prescreening for a dual palmar blood supply. Int J Cardiol 2007; 121:320-2.

[9] Kinnaird TD,Stabile E, Mintz GS,et al. Incidence,predictors, and prognostic implications of bleedingand blood transfusion following percutaneous coronary interventions. Am J Cardiol 2003;92:930-935.

[10] Fei T, Voeltz MD, Attubato MJ,et al.Predictors and impact of major hemorrhage on mortality following percutaneous coronary intervention from REPLACE-2 Trial. Am J Cardiol 2007;100:1364-1369.

[11] Yusuf S, Mehta SAR, Chrolavicius S,etal.Comparison of fondaparinuxand enoxaparin in acute coronary syndromes. N Engl J Med. 2006;354:1464-1476.

[12] Stone GW, McLaurin BT, Cox DA,et al. Bivalirudin for patients with acute coronary syndromes. N Engl J Med 2006;355:2203-2216.

[13] Stone GW, Witzenbichler B, Guagliumi G,wt al. Bivalirudin during primary PCI in acute myocardial infarction. N Engl J Med 2008; 358:2218-2230.

[14] Agostoni P, Biondi GG, de Benedictis ML,et al. Radial versus femoral approach for percutaneous coronary diagnostic and interventional procedures; systemic overview and meta analysis of randomized trials. J Am Coll Cardiol 2004; 44: 349-356.

[15] Chase AJ, Fretz EB, Warburton WP, et al. Association of the arterial access site at angioplasty with transfusion and mortality: the MORTAL study ( Mortality benefit 
of Reduced Transfusion after percutaneous coronary intervention via the Arm or Leg). Heart 2008; 94:1019-1025.

[16] Montalescot G, Ongen Z, Guindy R, et al. Predictors of outcome in patients undergoing PCI. Results of the RIVIERA study. Int J Cardiol 2007; 129: 379-387.

[17] Schaufele TG. Radial Access versus conventional Femoral Puncture : Outcome and Recourse Effectiveness in a daily routine.(Raptor) trial. American Heart association (AHA) 2009 Scientific Sessions.

[18] Lefevre T, Thebault B, Spaulding C, et al. Radial artery patency after percutaneous left radial artery approach for coronary angiography.The role of heparin.Eur Heart J 1995;16:293.

[19] Varenne O, Jegou A, Cohen R, et al. Prevention of arterial spasm during percutaneous coronary interventions through radial artery: the SPASM study. Cathet Cardiovasc Diagn 2006; 68:231-5.

[20] Jolly SS, Amlani S, Hamon M, Yusuf S, et al. Radial versus femoral access for coronary angiography or intervention and the impact on major bleeding and ischemic events: a systemic review and meta analysis of randomized trials. Am Heart J 2009; 157: 132-40.

[21] Brueck M, Bandorski D, Kramer W, et al. A randomized comparison of transradial versus transfemoral approach for coronary angiography and angioplasty. J am Coll Cardiol 2009;2: 1047-54.

[22] Jolly SS, Yusuf S, Cairns J, et al. Radial versus femoral access for coronary angiography and intervention in patients with acute coronary syndromes (RIVAL): a randomized, parallel group, multicentre trial. Lancet 2011; 377: 1409-1420.

[23] Bertrand OF, De Larochelliere R, Rodes- Cabau J, etal. Eraly Discharge After Transradial Stenting of Coronary Arteries ( EASY). A randomized study comparing same-day home discharge and abciximab bolus and infusion after transradial coronary stent implantation. Circulation 2006: 114: 2636-43.

[24] Saito S, Tanaka S, Hiroe Y,et al. Comaparative study on transradial approach vs transfemoral approach in primary stent implantatio for patients with acute myocardial infarction: results of the Test for Myocardial infarction by prospective Unicenter Randomization for Access sites (TEMPURA) trial. Catheter Cardiovasc Interv 2003; 59:26-33.

[25] Cantor WJ, Puley G, Natarjan MK, et al. Radial versus femoral access for emergent percutaneous coronary intervention with adjunct glyco-protein IIb/IIIa inhibition in acute myocardial infarction- The RADIAL- AMI pilot randomized trial. Am Heart j 2005; 150: 543-9.

[26] Hetherington SL, Adam Z, Morlet R, et al. Primary percutaneous coronary intervention for acute ST-segment elevation myocardial infarction: changing patterns of vascular access,radial versus femoral artery. Heart 2009;95:1612-18.

[27] Natarajan D and Vohra S. PCI via Radial Route for impending Anterior MI. 2009; http://www.tctmd.com

[28] Goldberg SL, Renslo R, Sinow R,et al. Learning curve in the use of the radial artery as vascular access in the performance of percutaneous transluminal coronary angioplasty. Cathet Cardiovasc diagn 1998; 44:127-52.

[29] Olivercona G. SCAAR registry: Transradial PCI cuts mortality in STEMI. 2011: EuroPCR.

[30] Bertrand OF, Rao SV, Pancholy S, et al. Transradial Approach for Coronary Angiography and Interventions : Results of the First International Transradial Pracvtice Surevey. J Am Coll Cardiol 2010;30: 1022-31. 


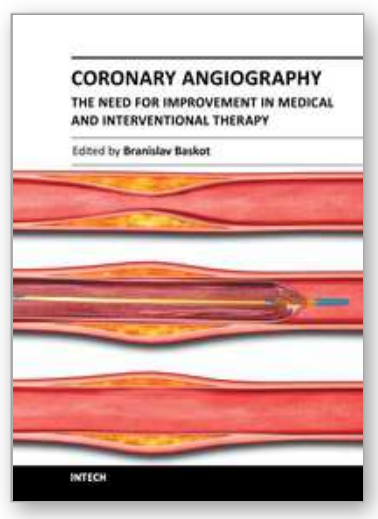

\section{Coronary Angiography - The Need for Improvement in Medical and Interventional Therapy}

Edited by Prof. Baskot Branislav

ISBN 978-953-307-641-6

Hard cover, 206 pages

Publisher InTech

Published online 06, September, 2011

Published in print edition September, 2011

In this book we examined a periprocedural complication of coronary angiography, and coronary intervention. That includes related to cardiac catheterization and diagnostic coronary angiography, and those that occur as a consequence of the specific equipment. However, improvements in devices, the use of stents, and aggressive antiplatelet therapy have significantly reduced the incident of major periprocedural complications. This book giving knowledge and experiences many of interventional cardiologists from all over the world, and provide possibility to recognize new approach in this domain. Book gives lecture on how we image and how we decide on what to treat, how to treat it, and then results of that treatment. They offer many answers to what we have today and what we will have tomorrow.

\section{How to reference}

In order to correctly reference this scholarly work, feel free to copy and paste the following:

Deepak Natarajan (2011). Trans Radial Access for Diagnostic Coronary Angiography and Percutaneous Coronary Interventions: Current Concepts and Future Challenges, Coronary Angiography - The Need for Improvement in Medical and Interventional Therapy, Prof. Baskot Branislav (Ed.), ISBN: 978-953-307-641-6, InTech, Available from: http://www.intechopen.com/books/coronary-angiography-the-need-for-improvement-inmedical-and-interventional-therapy/trans-radial-access-for-diagnostic-coronary-angiography-andpercutaneous-coronary-interventions-cur1

\section{INTECH}

open science | open minds

\author{
InTech Europe \\ University Campus STeP Ri \\ Slavka Krautzeka 83/A \\ 51000 Rijeka, Croatia \\ Phone: +385 (51) 770447 \\ Fax: +385 (51) 686166 \\ www.intechopen.com
}

\author{
InTech China \\ Unit 405, Office Block, Hotel Equatorial Shanghai \\ No.65, Yan An Road (West), Shanghai, 200040, China \\ 中国上海市延安西路65号上海国际贵都大饭店办公楼 405 单元 \\ Phone: +86-21-62489820 \\ Fax: $+86-21-62489821$
}


(C) 2011 The Author(s). Licensee IntechOpen. This chapter is distributed under the terms of the Creative Commons Attribution-NonCommercialShareAlike-3.0 License, which permits use, distribution and reproduction for non-commercial purposes, provided the original is properly cited and derivative works building on this content are distributed under the same license. 